\title{
A NEW METHOD FOR MEASURING SIALIC ACID LEVELS IN SERUM AND ITS APPLICATION TO RHEUMATIC FEVER ${ }^{1}$
}

\author{
By EUGENE L. HESS, ALVIN F. COBURN, RICHARD C. BATES,2 AND \\ PRISCILLA MURPHY \\ (From The Rheumatic Fever Research Institute, 3026 S. California Avenue, Chicago 8, Ill.)
}

(Submitted for publication August 6, 1956; accepted November 29, 1956)

Previous reports $(1-4)$ have indicated the clinical usefulness of a color reaction given by serum with the diphenylamine reagent of Dische. It has been shown that the purple color produced in this reaction is probably due to the presence of a deoxyhexose structure in the sialic acid molecule (5). Sialic acid, or a closely related substance, appears to be a common constituent of mucoproteins (glycoproteins) including orosomucoid of serum $(6,7)$. The color produced in the diphenylamine reaction reflects the concentration of the mucoproteins in the serum being tested. In our experience, and as reported by Anderson and Maclagan (8), the color developed with diphenylamine appears to be a specific reaction of mucoproteins. An elevation in the mucoproteins found in the alpha globulin fraction of serum is characteristic of many diseases ( 7$)$.

As pointed out in a previous report (4) a constant feature of the diphenylamine reaction was the concomitant rise in the color index of the "serum blank" associated with the increased color intensity of the serum samples tested. The "serum blank" in this instance was the combination of deproteinized serum with the sulfuric acetic acid mixture which did not contain diphenylamine.

This report will consider the chemical and clinical aspects of the "serum blank" reaction. It will be shown that the color produced when a mixture of sulfuric and acetic acids is heated with the deproteinized serum sample is also probably due to sialic acid. The simplicity of the test suggests its usefulness as a new method for measuring the intensity of inflammation.

\footnotetext{
1 Supported in part by a grant from the U. S. Atomic Energy Commission Contract AT(11-1) 366 with The Rheumatic Fever Research Institute and the U. S. Public Health Service Grant No. H26(C5).

2 U. S. Naval Hospital, Great Lakes, Illinois.
}

\section{METHODS}

The apparatus and procedures used in the electrophoretic studies have been previously described (9). Hexose analyses were made with the anthrone reagent according to the method of Dreywood (10) as modified by Morris (11), and Seifter, Dayton, Novic, and Muntwyler (12). A solution containing equal parts of galactose and mannose was used as a standard. Limitations of the anthrone method have been discussed by Sattler and Zerban (13) and by Yemm and Willis (14). Nitrogen and hexosamine determinations were made as described earlier (9). Sialic analysis was performed colorimetrically with the Dische diphenylamine reagent using sialic ${ }^{3}$ acid as a standard.

\section{CONDITIONS OF THE REACTION}

Interference caused by serum proteins other than the mucoproteins required the removal of these substances. The interfering materials were found to precipitate in 5 per cent trichloracetic acid. Indoles, pyrroles and tryptophan, produce color when heated with the reagent. The presence of tryptophan in the various serum proteins is therefore believed to be the chief source of interference.

\section{Precipitation step}

Time of heating. The intensity of the color obtained per unit volume of supernatant solution increased rapidly with the time of heating up to 5 minutes. For a heating period of 5 to 20 minutes no difference in intensity of color was found.

Trichloracetic acid concentration. The effect of changing the concentration of trichloracetic acid during the precipitation step was studied. No difference was found in the quantity of chromogenic material in the supernatant solution when the concentration of trichloracetic acid was varied from 5 to 20 per cent. With a concentration of trichloracetic acid less than 5 per cent a lower intensity of color was obtained.

\section{Color development step}

The concentration of sulfuric acid in the reagent was varied from 2.5 per cent to 40 per cent. Maximum color development occurred with a reagent containing 5 per cent sulfuric acid and 95 per cent glacial acetic acid.

${ }^{3}$ We wish to thank Dr. G. Blix for the generous sample of sialic acid. 


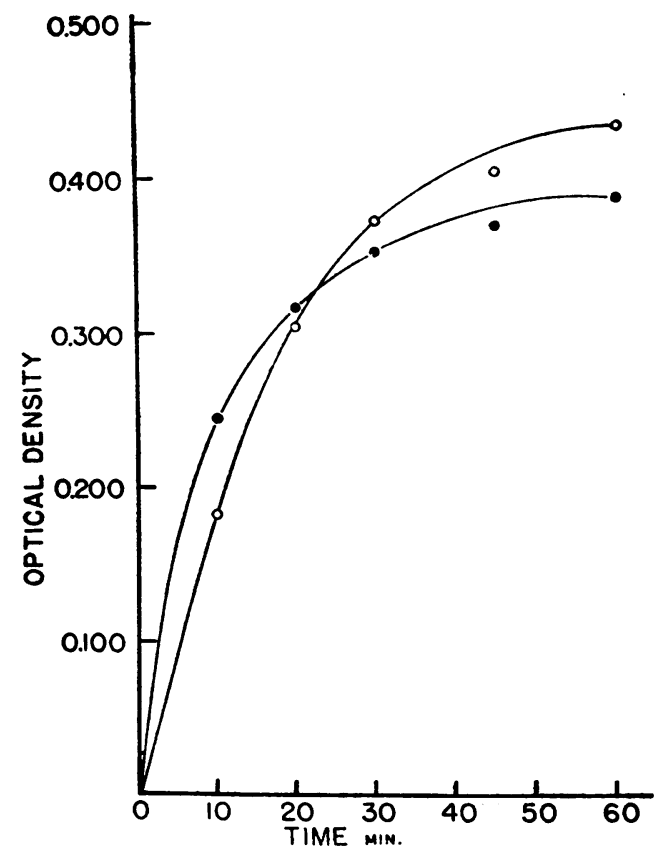

Fig. 1. The Effect of Time of Heating upon Optical Density Using a Mixture of 0.4 ML. of TCA Supernatant Solution and 5 ML. OF SUlfuric Acm REAGent

$\bigcirc$ Optical density readings measured immediately after cooling and allowing the solutions to come to room temperature.

- Optical density values obtained from the same solutions after standing 24 hours at room temperature.

The effect of time of heating on the color development can be seen in Figure 1. Since in each instance the intensity of the color did not change when the solution was allowed to stand at room temperature for an hour, a 30-minute heating period was selected as convenient for color development. The optical density readings, meassured after the heated reaction mixture stood 24 hours at room temperature, have also been plotted in Figure 1.

Aliquots of the supernatant solution varying from 0.2 to $1.0 \mathrm{ml}$. were heated with $5 \mathrm{ml}$. of reagent. Within this concentration range a Beer's law relationship obtained.

\section{SUGGESTED PROCEDURE}

\section{Reagents}

A solution of 10 per cent trichloracetic acid (TCA) was used to precipitate serum proteins.

The 5 per cent sulfuric acid reagent consisted of $5 \mathrm{ml}$. of concentrated sulfuric acid in $95 \mathrm{ml}$. of glacial acetic acid.

\section{Method}

To $1 \mathrm{ml}$. of serum in a $15-\mathrm{ml}$. Pyrex centrifuge tube was added $1 \mathrm{ml}$. of 10 per cent TCA. The TCA was added slowly with gentle shaking and stirring with a rod to insure complete mixing and fine flocculation of the precipitated protein. The tube was capped with a small beaker and placed in a boiling water bath for 5 minutes. After heating the tube was cooled in an ice bath for 5 minutes. The tube was shaken to remove precipitate adhering to the walls and centrifuged for 5 minutes at 1000 g. in an International Clinical Centrifuge.

Four-tenths $\mathrm{ml}$. of the supernatant solution was transferred to an $18 \times 150 \mathrm{~mm}$. rimless Pyrex tube and $5 \mathrm{ml}$. of the 5 per cent $\mathrm{H}_{2} \mathrm{SO}_{4}$ reagent was added from a $50-\mathrm{ml}$. burette. The tubes were capped with $10-\mathrm{ml}$. beakers and heated in a boiling water bath for exactly 30 minutes, during which time a pink color developed. The solution was cooled in an ice bath for 5 minutes, allowed to come to room temperature, transferred to a calibrated tube and read in a Model 6A Coleman Spectrophotometer at $530 \mathrm{~m} \mu$ against a 5 per cent $\mathrm{H}_{2} \mathrm{SO}$, reagent blank The results of all determinations have been expressed in terms of the uncorrected optical density. The test was reproducible to the nearest 0.010 optical density units.

The $18 \times 150 \mathrm{~mm}$. Pyrex tubes were examined for uniform optical properties. Tubes selected were uniform to \pm 0.005 optical density units at an optical density of 0.300 and at a wave-length of $530 \mathrm{~m} \mu$. This was well within the standard error of the method. The adaptor on the Model 6A Coleman Spectrophotometer was modified by reducing the vertical light path to $15 \mathrm{~mm}$. in order to accommodate a 5-ml. sample.

\section{CHEMICAL AND PHYSICAL STUDIES}

When serum is coagulated by heat, or with acids such as sulfosalicylic, perchloric and trichloracetic, there remains in the filtrate materials (15-18) which do not pass readily through the usual dialysis membranes.

Numerous workers have showed that the concentration of such substances in deproteinized serum was considerably increased in a wide variety of diseases (7). While a large number of methods (7) have been devised for measuring the concentration of these substances in serum very little effort has been directed towards their chemical and physical characterization. Winzler, Burk, and Hesselbach (19) reported that the materials prepared from sulfosalicylic acid filtrates using rat blood contained 6.4 per cent nitrogen and 31.1 per cent carbohydrate. The large carbohydrate (15 per cent) and hexosamine (11 per cent) content of material isolated from human serum by perchloric acid treatment led Winzler, Devor, Mehl, and Smyth to consider these substances to be mucoproteins (20). More recently Weimer, Mehl and Winzler, isolated and characterized a purified mucoprotein (21) which they have designated orosomucoid (7). Schmid (22) independently isolated the same substance.

There is evidence (23-26) that most mucoproteins are altered upon exposure to acid pH values. Under acid conditions apparently, some hydrolysis of the mucoprotein molecule occurs. Amongst the products of hydrolysis were found fragments which contained sialic acid and 
which were small enough to pass through the dialysis membrane (23).

The material considered in this report was found in the supernatant solution remaining after the precipitation of serum proteins from hot 5 per cent trichloracetic acid. An equal volume of 10 per cent trichloracetic acid was added with stirring to an aliquot of serum. The mixture was heated for 5 minutes in a boiling water bath and then rapidly cooled to room temperature. The supernatant solution, after removal of the precipitate by centrifugation, was neutralized with $6 \mathrm{~N} \mathrm{NaOH}$ to $\mathrm{pH} 7$. This solution was dialyzed for 48 hours against several changes of water, frozen and lyophilized. An average yield of $38 \mathrm{mg}$. per $100 \mathrm{ml}$. of serum was obtained. The material contained approximately 17 per cent hexoses, 3.5 per cent hexosamine, 13 per cent sialic acid and 5.8 per cent nitrogen. An aqueous solution of the product gave an ultraviolet absorption curve sigmoidal in shape without a maximum at $280 \mathrm{~m} \mu$. The optical density of the solution was approximately the same throughout the range 250 to $280 \mathrm{~m} \mu$. An extinction coefficient ( $\mathrm{E}_{380}^{1 \%}$ ) of about 2.8 was found. The absorption behavior suggested that the tyrosine and tryptophan content of the material was quite low. The nitrogen content, as well as a positive biuret and xanthoproteic test, indicated the presence of polypeptides.

The material was examined in two different buffer systems in the Tiselius apparatus. A single symmetrical peak which had zero mobility was observed at $\mathrm{pH} 8.6$ in 0.10 ionic strength Veronal buffer. Essentially the same behavior was found at $\mathrm{pH} 4.8$ in 0.10 ionic strength sodium acetate buffer. In the acetate system, in addition to the main peak which did not move, two small peaks with mobilities indicative of a negatively charged molecule were found. The zero mobility of the main

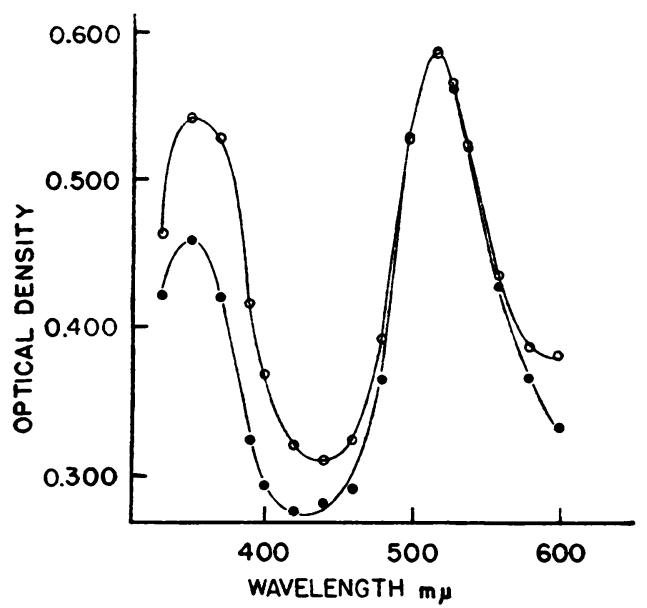

Fig. 2. Absorption Curves Obtained Using Diphenylamine Reagent

Serum preparation, $1.6 \mathrm{mg}$. per $1.5 \mathrm{ml}$. of solution added to $3 \mathrm{ml}$. reagent.

- Sialic acid, $0.20 \mathrm{mg}$. per $1.5 \mathrm{ml}$. of solution added to $3 \mathrm{ml}$. reagent.

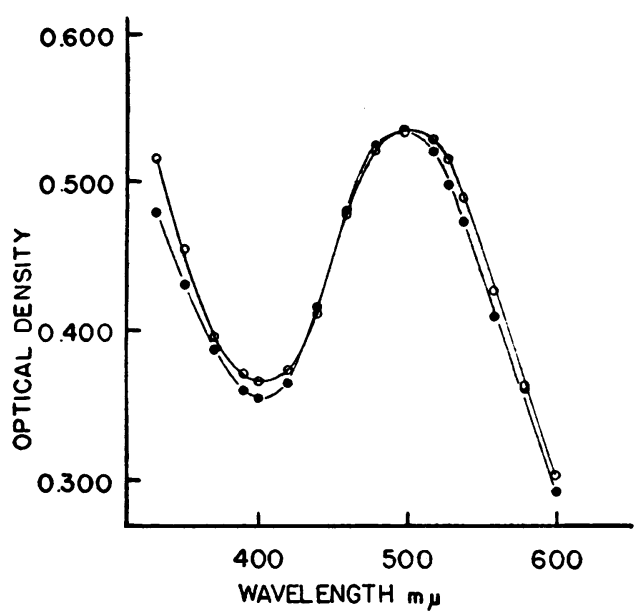

Fig. 3. Absorption Curves Obtained Using 5 Per Cent Sulfuric Acid Reagent

Serum preparation, $3.6 \mathrm{mg}$. in $0.4 \mathrm{ml}$. water added to $5 \mathrm{ml}$. reagent.

- Sialic acid, $0.40 \mathrm{mg}$. in $0.4 \mathrm{ml}$. water added to $5 \mathrm{ml}$. reagent.

component, found at two widely separated $\mathrm{pH}$ values, demonstrated that the material isolated as described above carried very little electrical charge. One can conclude, therefore, that a preponderance of the amino acids present in the polypeptide portion of the molecule were of the monoaminomonocarboxy type.

The samples used in the above electrophoretic experiments were recovered. The electrolyte was removed by dialysis against water and the samples were lyophilized. The recovered material contained 19 per cent hexoses, 12 per cent nitrogen and 6 per cent hexosamine but no sialic acid. Furthermore, a negative color reaction was obtained when the recovered sample was tested with the 5 per cent sulfuric acid reagent. The marked changes in the chemical composition of the recovered material from that of the original preparation suggested that extensive hydrolysis occurred while the recovered sample was dialyzing against water. A second possibility was that the dimensions of some of the molecules present in the original trichloracetic acid supernatant solution were such that these molecules passed through the Visking casing with difficulty. In the latter case the second period of dialysis was sufficient to remove these molecules.

The material isolated from the trichloracetic acid supernatant solution was tested with diphenylamine reagent and also with the sulfuric acid reagent. The absorption was measured with a model DU Beckman spectrophotometer and may be seen in Figures 2 and 3. The close similarity to the absorption curves obtained when a preparation of sialic acid ${ }^{\mathbf{3}}$ was tested in a similar manner may be seen in the same figures. This suggested that it was the presence of sialic acid or closely related structures in the serum preparation that was responsible for the color reaction. 
All purified mucoproteins tested at a concentration of $6 \mathrm{mg}$. per $\mathrm{ml}$. with the 5 per cent sulfuric acid reagent gave a positive color reaction and absorption behavior similar to that seen in Figure 3 . Those tested were ovomucoid, orosomucoid, 4 fetuin 5 and bovine tonsil mucoprotein. Purified gelatin gave no color. With crystalline bovine serum albumin at a concentration of $6 \mathrm{mg}$. per ml. a slight pink color with an absorption maximum at approximately $530 \mathrm{~m} \mu$ was obtained. The optical density in this case however, was only about 10 per cent of that obtained with orosomucoid. Of the various amino acids tested, which included proline, hydroxyproline, histidine, tyrosine, and tryptophan, only the last gave a color. Tryptophan at a concentration of $6 \mathrm{mg}$. per $\mathrm{ml}$. behaved, with respect to color development and absorption characteristics, in a manner indistinguishable from serum albumin.

The following sugars at a concentration of $5 \mathrm{mg}$. per ml. gave a negative test: sucrose, fructose, galactose, rhamnose and 2-deoxyglucose. Glucosamine did not produce a color.

Pyrrole and pyrrole derivatives yielded orange colored solutions with absorption maxima at about $480 \mathrm{~m} \mu$. With indole-3-acetic acid a pink color and a maximum at $530 \mathrm{~m} \mu$ in the absorption curve was observed.

The results of the above studies indicated that the reaction may be specific for sialic acid. Although the indole ring reacted with the reagent to give a somewhat similar color the intensity of color developed per unit weight of reactant was much less. For example, $30 \mu \mathrm{g}$. of sialic acid produced a color intensity comparable to that given by $6 \mathrm{mg}$. of tryptophan. In addition, and as discussed above, the indole ring differed from sialic acid with respect to the wavelength at which the absorption maximum occurred.

\section{RESULTS}

\section{Normal range}

The sialic acid ( $\mathrm{SiA}$ ) test was run on serum from 85 adults and children (male and female) in apparently good health. The normal range of optical density was calculated to be 0.227 to 0.303 . This represents two standard deviations ( $S D \pm$ 0.019) on either side of the arithmetic mean which was 0.265 . With the exception of six tests all normal sera fell within this range. Four of the six exceptions fell within three standard deviations. Included in these tests were a group of 16 quiescent rheumatic children ranging in age from 10 to 16 years. These children had not been ill during the previous six months. The normal range for the

\footnotetext{
\& Dr. Henry Weimer kindly provided the sample of orosomucoid.

${ }^{5} \mathrm{We}$ are indebted to Dr. H. F. Deutsch for the sample of fetuin.
}

TABLE I

The range of SiA values in three diseases

\begin{tabular}{lll}
\hline \hline Acute rheumatic fever & (Cases 37) & 0.372 to 0.592 \\
Tuberculosis & (Cases 11) & 0.292 to 0.665 \\
Cancer & (Cases 6) & 0.332 to 0.590 \\
\hline
\end{tabular}

sialic acid test for these 16 was calculated to be 0.216 to 0.304 . The mean was 0.260 , and the standard deviation was 0.022 .

\section{Range for disease states}

Both sialic acid and DPA (1) tests were run on aliquots of serum from patients in different stages of pulmonary tuberculosis, tuberculous meningitis, cancer and rheumatic fever. The sialic acid test was elevated during the acute phase of these diseases in all patients as shown in Table I.

Serial determinations were made in parallel with DPA tests on a group of rheumatic fever patients at Great Lakes Naval Training Station. All of these patients were young male adults with typical attacks of rheumatic fever which met Jones' criteria as recently modified (27). The results from the two tests, made on aliquots of serum, were compared. The average optical density reading with the sialic acid test during acute stages of rheumatic fever, as measured on 42 subjects, was 0.465 . The results have been divided into four groups :

a. Agreement-DPA test positive, SiA test positive, 178 out of 318 .

b. Agreement-DPA test negative, SiA test negative, 95 out of 318 .

c. Disagreement-DPA test positive, SiA test negative, 2 out of 318 .

d. Disagreement-DPA test negative, SiA test positive, 41 out of 318 .

Serial determinations showed that the SiA test, compared with the E.S.R. (Wintrobe) test, was a more persistent expression of rheumatic inflammation. The return to normal $\mathrm{SiA}$ values in 18 patients studied was slower in 12, and coincidental in 5. In one case the E.S.R. followed the SiA. The average time difference for a return to normal values was 2 weeks longer for the $\mathrm{SiA}$ test than for the E.S.R. (Wintrobe) test. Previous studies $(2,4)$ showed that the DPA, C-reactive protein, and E.S.R. (Westergren) rise and fall 

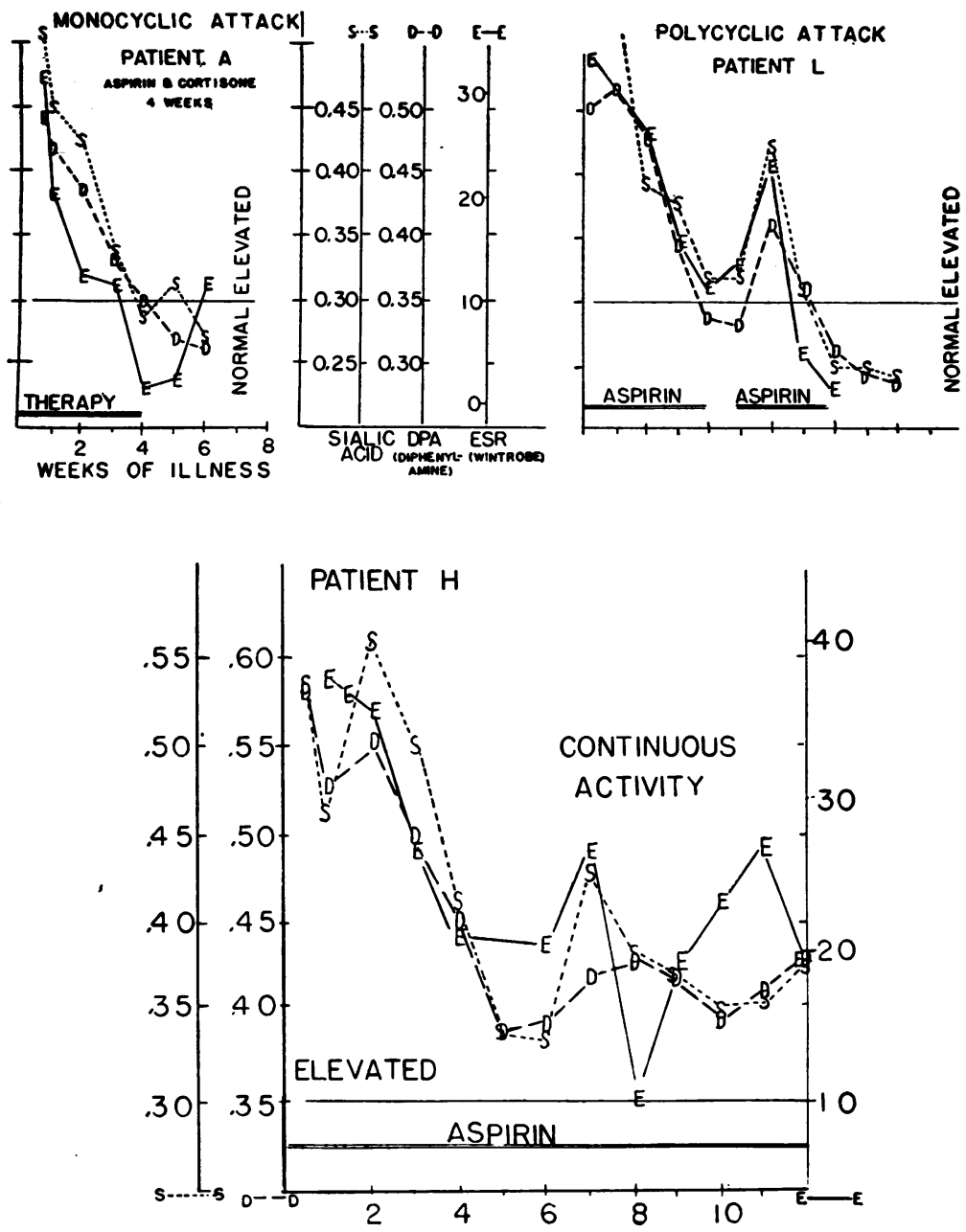

Fig. 4. The Relationship between the SiA, DPA and E.S.R. Determinations during the Course of Rheumatic Attacks (Monocyclic, Polycyclic and Continuous)

S-refers to the sialic acid level

$\mathrm{D}$-indicates the color intensity of the diphenylamine reaction

$\mathrm{E}$-is the sedimentation rate of erythrocytes (Wintrobe).

in parallel. Furthermore, the DPA elevation may continue after the $\mathrm{C}$-reactive protein is negative, and usually persists after a normal level is reached by the E.S.R. (Westergren). The SiA determinations in relation to E.S.R. (Wintrobe) are shown in Figure 4.

\section{DISCUSSION}

Evidence has been presented that when serum proteins have been precipitated with hot 5 per cent trichloracetic acid the supernatant solution after dialysis consisted chiefly of uncharged molecules. The substances contained sizable amounts of hexoses, hexosamine and sialic acid, as well as polypeptides. The lability of mucoproteins, when exposed to acids, and the difference in the amount of the material obtained, depending upon time and temperature factors during precipitation, suggested that these substances were probably fragments of those mucoprotein molecules which are normally present in serum.

Additional evidence indicated that these substances were found in elevated amounts in serum samples from a variety of diseases in which serum mucoproteins are known to be elevated (7). 
Both chemical and spectrophotometric evidence implicated sialic acid as the structure responsible for color development. Substances tested which did not contain sialic did not produce the characteristic color when heated with the reagent. The material recovered from electrophoretic experiments, which no longer contained sialic acid, lost the capacity to produce the characteristic pink color.

Four other methods have been reported for measuring the sialic acid levels in blood serum (6). These reactions are: 1) Bial's reaction, 2) the direct Ehrlich reaction, 3) the diphenylamine reaction, 4) the tryptophan-perchloric acid reaction (6). Until such time as a quantitative study comparing the various methods has been made it is not possible to recommend any one method as being either quantitatively or qualitatively more reliable than another. The method suggested in this report, although somewhat less sensitive than the Bial and the diphenylamine reactions, is recommended for clinical use on the basis of its simplicity.

\section{SUMMARY}

1. A new colorimetric procedure has been described for measuring mucoprotein levels in serum. The only reagents employed are trichloracetic, sulfuric, and acetic acids. The simplicity and the sensitivity of the method, as well as the reproducibility of results, recommend its use.

2. The chromophoric substance was found to be present in the supernatant solution when the serum proteins were precipitated with hot trichloracetic acid. Chemical and physical characterization studies indicated that the substances remaining in the supernatant solution were non-dialyzable, uncharged molecules consisting of monoaminomonocarboxy type polypeptides combined with hexoses, hexosamine and sialic acid.

3. Both chemical and spectrophotometric evidence implicated sialic acid as the structure responsible for the color produced.

4. The optical density values for normal, rheumatic fever, cancer, and tuberculosis sera are reported. Serial determinations on rheumatic fever patients indicated that the method described above, was more sensitive and consistent than the erythrocyte sedimentation rate as an expression of rheumatic activity.

\section{REFERENCES}

1. Ayala, W., Moore, L. V., and Hess, E. L., The purple color reaction given by diphenylamine reagent. I. With normal and rheumatic fever sera. J. Clin. Invest., 1951, 30, 781.

2. Coburn, A. F., Moore, L. V., and Haninger, J., The serum diphenylamine reaction in rheumatic fever. Arch. Int. Med., 1953, 92, 185.

3. Coburn, A. F., and Haninger, J., The serum diphenylamine (DPA) reaction: an index for screening anti-inflammatory agents. Tr. A. Am. Physicians, 1953, 66, 308.

4. Coburn, A. F., Bates, R. C., Hahn, J. W., and Murphy, P., Further observations on the diphenylamine (DPA) reaction as an index of inflammation. J. Chronic Dis., 1956, 3, 140.

5. Hess, E. L., Hahn, J. W., and Ayala, W., Structures responsible for the characteristic purple color development in the diphenylamine reaction with serum. Proc. Soc. Exper. Biol. \& Med., 1956, 91, 528.

6. Werner, I., and Odin, L., On the presence of sialic acid in certain glycoproteins and in gangliosides. Acta soc. med. Upsal., 1952, 57, 230.

7. Winzler, R. J., Determination of serum glycoproteins in Methods of Biochemical Analysis, 1955, Vol. 2, p. 279.

8. Anderson, A. J., and Maclagan, N. F., The isolation and estimation of urinary mucoproteins. Biochem. J., 1955, 59, 638.

9. Hess, E. L., Ayala, W., and Herranen, A., The separation and properties of a mucoprotein from a lymphatic organ. J. Am. Chem. Soc., 1952, 74, 5410.

10. Dreywood, R., Qualitative test for carbohydrate material. Indust. \& Engin. Chem. (Anal. Ed.), 1946, 18, 499.

11. Morris, D. L., Quantitative determination of carbohydrate with Dreywood's anthrone reagent. Science, 1948, 107, 254.

12. Seifter, S., Dayton, S., Novic, B., and Muntwyler, E., The estimation of glycogen and the anthrone reagent. Arch. Biochem. \& Biophys., 1950, 25, 191.

13. Sattler, L., and Zerban, F. W., Limitations of the anthrone test for carbohydrates. J. Am. Chem. Soc., 1950, 72, 3814.

14. Yemm, E. W., and Willis, A. J., The estimation of carbohydrates in plant extracts by anthrone. Biochem. J., 1954, 57, 508.

15. Zanetti, C. U., Sull' ovimucoide e spora un nuovo glicoproteide contenuto nel siero di sangue. Ann. di chim. e di farm., 1897, 26, 529.

16. Brdička, R., Novák, F. V., and Klumpar, J., Critical examination of the polarographic test for cancer in deproteinated sera. Acta radiol. et cancerol. bohem. et morav., 1939, 2, 27.

17. Neuberg, C., Strauss, E., and Lipkin, L. E., Convenient method for deproteinization. Arch. Biochem., 1944, 4, 101. 
18. Puech, R., and Cristol, P., A propos de l'indice de désamination, signification de l'indice de polypeptidémie et de l'indice de désamination (2). Bull. et mem. Soc. med. d. hôp. de Paris, 1926, 50, 1828.

19. Winzler, R. J., Burk, D., and Hesselbach, M., Blood proteose and cancer. J. Nat. Cancer Inst., 1944, 4, 417.

20. Winzler, R. J., Devor, A. W., Mehl, J. W., and Smyth, I. M., Studies on the mucoproteins of human plasma. I. Determination and isolation. J. Clin. Invest., 1948, 37, 609.

21. Weimer, H. E., Mehl, J. W., and Winzler, R. J., Studies on the mucoprotein of human plasma. V. Isolation and characterization of a homogeneous mucoprotein. J. Biol. Chem., 1950, 185, 561.

22. Schmid, K., Preparation and properties of serum and plasma proteins. XXIX. Separation from human plasma of polysaccharides, peptides, and proteins of low molecular weight. Crystallization of an acid glycoprotein. J. Am. Chem. Soc., 1953, 75, 60.

23. Hess, E. L., and Murphy, P., Unpublished results.

24. Surgenor, D. M., Strong, L. E., Taylor, H. L., Gordon, R. S., Jr., and Gibson, D. M., The separation of choline esterase mucoprotein, and metal-combining protein into subfractions of human plasma. J. Am. Chem. Soc., 1949, 71, 1223.

25. Blix, G., and Odin, L., Isolation of sialic acid from gangliosides. Acta chem. Scandinav., 1955, 9, 1541.

26. Yamakawa, T., and Suzuki, S., Presence of serolactaminic acid and glucosamine as constituents of serum mucoprotein. J. Biochem., (Japan), 1955, 42, 727.

27. Jones Criteria (modified) for guidance in the diagnosis of rheumatic fever. Mod. Concepts Cardiovas. Dis., 1955, 24, 291. 